\title{
Serving Many Masters: Public Accountability in Private Policy
}

\section{Implementation}

This is the accepted version of

Thomann, E., Hupe, P. and F. Sager. 2017. Serving Many Masters: Public Accountability in Private Policy Implementation. Governance, DOI: 10.1111/gove.12297.

\begin{abstract}
In recent decades, the introduction of market principles has transformed public service delivery into a hybrid. However, little is known about how these changes are reflected in the attitudes of private implementing agents: the hybridization literature neglects individuals, and street-level bureaucracy research has disregarded hybridization. This paper extends Hupe and Hill's accountability regimes framework to introduce the market as an additional accountability regime alongside state, profession, and society. Using a configurational approach, the paper explores how public and private food safety inspectors in Switzerland perceive the multiple norms for behaviour stemming from their environment. Results suggest that the plural accountabilities of for-profit street-level bureaucrats can increase the dilemmas involved in their work. Under certain circumstances, for-profit street-level bureaucrats have particular difficulties reconciling rule pressure with market incentives and client demands. The extended accountability regimes framework fruitfully captures such dilemmas and helps identify suitable governance responses.
\end{abstract}

\section{Keywords}

Hybridization, for-profit policy implementation, public accountability, public-private arrangements, street-level bureaucracy 


\section{Introduction}

This paper extends Hupe and Hill's accountability regimes framework (2007) to account for market mechanisms in policy implementation. Recent decades have seen the substitution of public ownership, planning or centralized administration for private ownership, competition and (quasi-)market incentives (Koppell 2010; Levi-Faur 2011). Public sector reforms like New Public Management (NPM), privatization, decentralization, and contracting-out have created a market-corporate type of bureaucracy in which governmental, non-profit and corporate actors cooperate in policy implementation (Considine and Lewis 1999, 2003). Hence, workers in the private sector now represent public policy to the people (Smith and Lipsky 2009, 13). Hybrid policy implementation operates at the intersection between public and private, for-profit and non-profit sectors: public policy goals coexist with market-led goals such as efficiency and profit (Deleon 1998; Verbruggen and Havinga 2017). In consequence, frontline workers (also called street-level bureaucrats) have to balance the rationalities and demands of the state and the market (Skelcher and Smith 2015). This may lead to a 'basic tension between performance and representation (...) in the administrative system in many countries' (Pierre 2009, 603). The marketization of policy implementation bears the 'risk for organizations and their workforces of losing sight of their purpose and values in the quest for organizational survival and efficiency’ (Ebrahim et al. 2014: 82).

Koppell $(2010,546)$ has urged Public Administration scholars to move 'beyond the lines that define our field but do not reflect contemporary realities'. This implies 'expanding our understanding of 'administration' to include market-based programs' (ibid, 547). Organizational and managerial responses to multiple institutional demands in hybrid - often non-profit - settings are relatively well-explored (e.g., Ebrahim et al. 2014; Fossestøl et al. 
2015; Seibel 2015). However, street-level bureaucracy research has not caught up with these changing faces of bureaucracy (Saetren 2014). We know that different governance models can demonstrably influence frontline staff's work orientations (Considine and Lewis 1999, 2003). Yet how individuals at the frontline empirically experience, assess and manage competing demands within hybrid for-profit implementation settings is not yet fully understood (Mashaw 2005; Pache and Santos 2010, 456).

This paper analyses private veterinarians in Switzerland. By law, they are required to control livestock farmers' compliance with food safety regulations in primary production. Livestock farmers pay them for these controls. Since Considine and Lewis (1999, 2003), few scholars have analysed private sector actors who implement public policies for profit (e.g., Considine et al. 2011; Dias and Maynard-Moody 2006). Little is known about whether the attitudes of these for-profit street-level bureaucrats differ from those of their public counterparts, and what such differences may imply (Buffat 2014; Oberfield 2016). Research into street-level bureaucracy arguably lacks an analytic instrument that systematically captures the particularities of forprofit policy implementation. This paper provides such a tool and empirically explores whether and how tensions like those mentioned above materialize at the street level.

To develop this tool, this paper combines insights on hybrid organizations with street-level bureaucracy research. The concept of 'public accountability' captures the way in which rules, normative and social expectations influence individual policy implementers in their social interactions (Pache and Santos 2010, 457). Street-level bureaucrats

see themselves confronted with multiple demands for accountable behaviour. Particularly on the scale of the individual, the different values implied and action imperatives stemming from these varying sources may produce tensions and will often be contradictory, posing inescapable dilemmas for these officials (Hupe 
and Hill 2007, 290).

Ebrahim et al. $(2014,82)$ distinguish for what an organization is accountable, and to whom it is accountable. Along these lines, Hupe and Hill's (2007) accountability regimes framework identifies three sources of accountability for street-level bureaucrats: formal rules from the state (here: the food safety regulations), standards from the profession (the veterinary discipline), and expectations from society (livestock farmers) (Hupe and Van der Krogt 2013, Hupe and Buffat 2014). However, research on hybrid organizations tells us that customers and shareholders also place demands on for-profit street-level bureaucrats. Market mechanisms imply a fourth type of accountability: the economic incentives stemming from the market that emphasize profit, competition, entrepreneurship, and efficiency in policy implementation (Ebrahim et al. 2014; Mashaw 2005; Seibel 2015; Skelcher and Smith 2015).

Based on this extended accountability regimes framework, we move beyond predominantly conceptual, discursive or normative approaches toward accountability in order to make the concept measurable (see Bovens et al. 2014; Schillemans and Busuioc 2016). We address two empirical questions. First, how do public and private (for-profit) street-level bureaucrats perceive the multiple demands from their environment, and what tensions arise? Second, are there particular patterns? We explore three hypotheses about how the attitudes of public and private street-level bureaucrats might differ within the hybrid enforcement structure of the Swiss Ordinance on Veterinary Medicinal Products (OVMP). This case selection enables us to compare public and private street-level bureaucrats who implement the same policy. The fact that the state hardly holds them formally accountable makes them a particularly telling case for market-oriented accountability. Based on original survey data (Sager et al. 2012), we apply a configurational approach using fuzzy sets (Ragin 2000) to depict public-only, private-only, and mixed types of street-level attitudes. 
We find that in terms of professionalism, the attitudes of for-profit veterinarians and government employed veterinarians are similar. However, they diverge in one key dimension: private veterinarians experience more dilemmas of policy implementation than their government-employed colleagues. Specifically, they are more torn by their obligations to their clients, policy, and market pressure. This finding suggests that government employed streetlevel workers may feel a less conflicted obligation to serve the general public.

We next elaborate the extended accountability regimes framework and specify three hypotheses. We then outline the empirical case, the data and methods used. Section four presents the empirical findings. The paper concludes by discussing the implications.

\section{Extending the accountability regimes framework}

According to Bovens et al. (2014, 6-7, emphasis added),

accountability is about $(\ldots)$ answerability towards others with a legitimate claim to demand account. Accountability is then a relational concept, (...) linking agents and others for whom they perform tasks or who are affected by the tasks they perform. (...) Accountability is furthermore a retrospective - ex post activity. Finally accountability is a consequential activity as anyone who is being held accountable may testify (...) Public accountability is accountability in, and about, the public domain.

Who exercises accountability toward whom - for example, vertically between managers and employees, and horizontally, between peers - is an empirical question (Behn 2001). This means that many types of accountability are possible (Deleon 1998; Mashaw 2005).

In the study of street-level bureaucracy, Hupe and Hill's (2007) accountability regimes 
framework has evolved as a central concept (e.g., Brodkin 2012; Thomann 2015; Bovens et al. 2014; Buffat 2014; Hupe and Van der Krogt 2013; Hupe and Buffat 2014). The term 'public accountability' captures the social relationships of street-level bureaucrats in which they feel an obligation to explain and to justify their conduct to some significant other (Hupe and Hill 2007, 286). 'Accountability regimes' are sets of guidelines for action that prevail within social relationships. Actors ask and give each other explanations and justifications of their actions. 'Action prescriptions' are norms and demands about how street-level bureaucrats should preferably behave; they emerge at three levels: from institutionalized contexts; the organization and work circumstances; and individual characteristics. The resulting types of (subjective or objective) pressure add up to 'work pressure' at the street level. To analyse for-profit streetlevel bureaucrats (Koppell 2010), we extend Hupe and Hill's (2007) threefold accountability regimes framework and introduce an additional customer- and shareholder-oriented accountability regime with incentive pressure from the market; see Table 1.

-- Insert Table 1 here-

Public-administrative accountability refers to bureaucratic control or managerial approaches whose source is the state, that is, the law, political appointees, and administrative authorities (Hupe and Hill 2007, 288-289). Rule pressure means political or legal action prescriptions such as laws, public policies, and broader political ideologies. Implementing organizations provide political-administrative, organizational, and managerial imperatives, structures, and objectives (May and Winter 2009, 455). Street-level bureaucrats experience rule pressure, for instance, through recruitment processes, caseloads, performance targets, and specific tasks (Hupe and 
Van der Krogt 2013, 62).

As Mashaw $(2005,21)$ highlights, market mechanisms create particular accountabilities for street-level bureaucrats:

In $(\ldots)$ markets, $(\ldots)$ producers are responsible to consumers $(\ldots)$ for their products' quality and price. The process or mechanism of accountability is market competition (...). The standards are customers' individual preferences. The effects of accountability to the market are, immediately, the willingness of consumers to buy the product at the offered price and, ultimately, a product's capacity to maintain itself in the market.

Following research on hybrid organizations (Ebrahim et al. 2014; Paché and Santos 2013; Seibel 2014), we can hence add an additional, essentially customer- and shareholder-oriented accountability regime that follows market principles. In the marketplace, actors adjust supply and demand. To survive economically in a competitive environment, for-profit service providers must generate profits and satisfy the customers, upon whom they depend. While clients are the policy's target group, the term customer depicts an economic relationship. If the clients are also their customers, they directly hold for-profit street-level bureaucrats accountable (Mashaw 2005; Sager et al. 2014). For example, food safety auditors who are paid by their clients tend to reduce the rigor of audits (Lytton and McAllister 2014).

The market emphasizes the values of maximal efficiency, profit, financial transparency, and growth (Tummers et al. 2012b, 2). Agencies should behave in entrepreneurial ways and pursue market-driven solutions. They deliver services in competition with other providers, whose basis is performance quality. Decentralized, supervised procedures allocate key resources according to output performance (Considine et al. 2011, 812, 816). Street-level bureaucrats have to economize their resources by maximizing output while also minimizing costs. For instance, clients have to be placed in jobs as quickly and cheaply as possible (Dias and Maynard-Moody 
2006). These mechanisms result in incentive pressure. ${ }^{1}$

Professional accountability refers to how training and professional socialization creates vocational pressure (Hupe and Van der Krogt 2013, 63f). Professional peers and team members practise collective self-management based on their expertise (Mashaw 2005; Hupe and Hill 2007, 290). Professional values, norms, and attitudes provide street-level bureaucrats with a 'set of rules one would follow if allowed to act professionally as a member of a professional community' (Tummers et al. 2012b, 4) - for instance, best practice and quality standards (Deleon 1998).

Finally, the shared citizenship of street-level bureaucrat and client results in participatory accountability (Hupe and Hill 2007, 290). The media, socio-cultural characteristics of the clientele, third parties and organized consumers of public services all create societal expectations of policy implementers (Hupe and Buffat 2014). This societal pressure translates into the expectations of individual clients toward frontline workers (Mashaw 2005). Street-level bureaucrats usually have a clear perception of their clients' needs. They want to make a difference and contribute to a larger purpose (Dias and Maynard-Moody 2006, 201; Tummers 2012, 218).

Street-level bureaucrats are simultaneously exposed to several accountability regimes. Each of these regimes provides a set of norms to which they can allocate their attention and that may

\footnotetext{
${ }^{1}$ Governments adopting the NPM ideology have partly integrated market-driven incentive pressure into rule pressure (Considine et al. 2011). This can lead to dilemmas between differing rule pressures (e.g., Dias and Maynard-Moody 2006).
} 
then guide their behaviour (Hupe and Buffat 2014). To capture this, we define norm reference as the intensity with which street-level bureaucrats allocate their attention to and identify with particular action prescriptions. Norm reference captures subjective perceptions of actors, not objective behaviour. ${ }^{2}$ We observe strong reference to rule pressure when caseworkers perceive the policy to lead to its stated goals and agree with the policy's goals (May and Winter 2009, 460; Tummers 2012; Tummers et al. 2012a). For example, a veterinarian might be convinced that the inspections help ensure food safety.

Multiple action prescriptions can create competing demands and values - the dilemmas that all street-level bureaucrats face to some degree (Lipsky 1980/2010). Dilemmas prevail when some action prescriptions are at the expense of or incongruent with other demands (Koppell 2005, 99; Tummers et al 2012). The literature on hybrid organizations refers to similar phenomena as 'competing institutional logics' (Ebrahim et al. 2014; Pache and Santos 2013). Our analysis focuses on horizontal accountability dilemmas between rule pressure and incentive, vocational or societal pressure, rather than on vertical dilemmas at different levels of aggregation (Hupe and Van der Krogt 2013). An example of a dilemma between rule and incentive pressure would be when a veterinarian's inspection duties diminish profits or alienate customers (Thomann et al. 2016; see also Dias and Maynard-Moody 2006). Rule and vocational pressure clash when street-level bureaucrats perceive the demands of the policy to be incongruent with their professional values, norms, and attitudes (Tummers et al. 2012, 4, 5). Our food safety

\footnotetext{
${ }^{2}$ Assessing the relationship between perceptions and behaviour goes beyond the scope of this study (see Tummers 2012, 517).
} 
inspectors, for example, may feel that the number and content of the inspections they should carry out is inadequate. Finally, the perceived lack of an added value of the policy to socially relevant goals or for the clients would indicate a dilemma between rule pressure and societal pressure (Tummers et al. 2012a, 4, 13). For example, the private veterinarians might feel that their controls are useless for the livestock farmers.

Table 2 summarizes how street-level bureaucrats may refer to different norms and what dilemmas might arise with rule pressure. This results in seven attitudes.

-- Insert Table 2 here -

\section{Hypotheses}

We explore three assumptions about how the attitudes of public and for-profit street-level bureaucrats might differ. A first hypothesis acknowledges that overarching sector-specific accountabilities, so-called "institutional logics", guide frontline staff. This would imply a distinct logic of market actors (Considine and Lewis 1999; Fossestøl et al. 2015; Pache and Santos 2010, 2013; Skelcher and Smith 2015). We call this the sectoral hypothesis: For-profit street-level bureaucrats typically refer strongly to the norms of the market, while this is not typical for public street-level bureaucrats. Conversely, a second hypothesis captures the results of previous studies that observed no systematic differences between the perceived accountability and performance of public and for-profit street-level bureaucrats (Considine et al. 2011; Oberfield 2016). As professionals conducting similar work (Lipsky 1980/2010), they ought to share similar attitudes. Hence, according to the categorical hypothesis, norm reference and dilemmas do not systematically differ between public and private actors. However, third, 
in hybrid environments, frontline workers have 'to be accountable to a multiplicity of actors, expectations, and in varying conditions' (Buffat 2014, 84; see also Busuioc and Lodge, 2016). Facing many different and sometimes contradictory accountabilities, their attempts at being accountable in multiple senses increase the potential for competing demands (Deleon 1998; Koppell 2005). We call this the private dilemma hypothesis: For-profit street-level bureaucrats typically experience multiple dilemmas simultaneously, while this is not as salient with public or mixed (i.e., shared by public and private veterinarians) street-level attitudes.

\section{Data and methods}

Data

We explore these hypotheses in the context of the decentralized hybrid implementation structure of the OVMP. This policy regulates veterinary drugs for livestock to ensure animal health and food safety (Sager et al. 2012). Its main target groups are the private veterinarians who dispense the drugs, and the livestock farmers who administer the drugs to the animals. To enforce the OVMP, public inspectors of 23 regional (cantonal) veterinary offices, named public veterinarians, carry out official on-site inspections every five years in veterinarians' practices, and (until 2012) every ten years on livestock farms. Additionally, the private veterinarians monitor the livestock farmers themselves. Written agreements between veterinarians and livestock owners entail biannual visits to the farms. During these visits, the veterinarians are legally obliged to check the farmers' compliance with the OVMP. Furthermore, a private veterinarian must supervise each on-site fabrication of medicated feedstuffs (OFM).

\section{-- Insert Table 3 here --}

While their jobs are not identical, public and private veterinarians share important analytic 
features that make them comparable, see Table 3. According to Lipsky (1980/2010, xi), streetlevel bureaucrats are professionals who implement a public policy, interact directly with clients, and enjoy high discretion and relative autonomy from organizational authority. Regulatory processes entail a) agenda-setting and decision-making, b) adoption and implementation, c) monitoring compliance, $\mathrm{d}$ ) enforcement and e) evaluation and review (Verbruggen and Havinga 2017). As implementing agents, both public and private veterinarians are primarily active in phase c, while also having some tasks in phase d. They oversee compliance of farmers with the same official regulations, although with differing frequencies. Their control tasks overlap: they check the health status of livestock as well as the facilities and documentation concerning the supply, use, and storage of drugs. This always entails a physical inspection of the production sites together with the farmer in order to detect or prevent violations of the regulations. Public veterinarians can sanction livestock farmers through fines and other administrative measures, while private veterinarians are legally obliged to refrain from prescribing and selling veterinary drugs such as antibiotics, or even report to authorities if livestock farmers do not comply with the regulations.

Next to direct interaction with livestock farmers as clients when visiting farms, public and private veterinarians also share their professional background as trained veterinarians. All public veterinarians have previously worked as private veterinarians. They know each other and attend professional events together. Finally, both public and private veterinarians do not operate within a strong organizational environment, and they typically have no line managers above them. Federal oversight is very weak for public veterinarians and absent from private veterinarians (Sager et al. 2014, 487). The federal administration does not gather data about the inspection activities of neither public nor private veterinarians. Hence, failure to carry out their duties has no consequences. Public veterinarians do not monitor the private veterinarians' 
activities as implementing agents either. This creates similarly high levels of autonomy.

As Verbruggen and Havinga (2017) highlight, hybridization implies that actors with diverging rationalities are involved in regulation - here, public and for-profit implementers. Second, the same actors can simultaneously have several regulatory roles. Indeed, private veterinarians are simultaneously implementers and target group of the policy. Third, hybridization often entails self-regulatory and multi-level elements. In our case, the state delegates monitoring activities to the private sector, and the decentralized federal setting impedes effective monitoring and enforcement on the implementing agents.

As a result, public and private veterinarians face different incentive structures. Public veterinarians are employed by the state, while private veterinarians are self-employed. This arrangement has a strong for-profit element: The private veterinarians charge the farmers for their enforcement activities and depend economically upon them. The public and private streetlevel bureaucrats also differ in terms of when and how they interact with the clients. The private veterinarians check farmers much more regularly. Besides their control function, the private veterinarians are primarily (for-profit) service deliverers. Furthermore, they have a mutually interdependent power relationship with the clients. Therefore, private veterinarians might refer more strongly to societal pressure than public veterinarians. They are likely to be prone to the customer-driven type of accountability. Conversely, the public inspectors have an asymmetric power relationship with the farmers. They interact with each individual farmer only once a decade. Some cantonal inspectors also deliver (non-profit) information and counselling services, but only to a limited extent. Generally, their reference to participatory and market accountability should be weaker.

In summary, both public and private veterinarians have identical professional backgrounds, implement the same overarching policy, interact with the same target group, and enjoy great 
autonomy (Sager et al. 2014, 487). These commonalities (marked bold in Table 3) enable us to compare their attitudes toward the diverse action prescriptions of this policy. Additionally, the hybrid structure of the OVMP creates differences in the work contexts, incentive structures and accountabilities of public and for-profit policy implementers. We will now analyse the consequences of these differences.

Data was gathered during the formative evaluation of the OVMP in 2012. We conducted semistructured telephone surveys with cantonal public veterinarians $(\mathrm{N}=21)$. The cantons of Ticino and Zug did not participate in the interviews, but Liechtenstein is subject to the OVMP. An online questionnaire containing both open and closed questions (published in Sager et al. 2012) was sent to all registered Swiss private veterinarians (response rate of 25 per cent, $\mathrm{N}=371$ ). After excluding 78 cases with missing values and private configurations with low empirical relevance (see below), the sample comprises 18 public and 269 private veterinarians. Rather than being a result of selection bias, their unequal proportions represent the implementation setting at hand.

\section{Methodology}

A street-level bureaucrat experiences and responds to multiple simultaneous action prescriptions. Set-theoretical configurational analysis (Ragin 2000) captures that street-level bureaucrats display a combination of attitudes, rather than focusing on single accountabilities. We analyse the prevalence of those attitudes listed in Table 2, where norm reference can be strong or weak, and dilemmas can be present or absent. Given that there are seven attitudes in Table 2, we can build a 'truth table' with $2^{7}=128$ possible configurations of street-level attitudes, not all of which are found empirically.

The rationale of the analysis is straightforward. To assess our hypotheses, we provide a simplified description of those configurations of attitudes that were observed among public 
veterinarians only, among private veterinarians only, or that are shared by public and private veterinarians (mixed attitudes). Rather than merely listing all observed configurations, we additionally reduce these configurations to their parsimonious core. For example, if we have a combination $\mathrm{A}$ and $\mathrm{B}$ and $\mathrm{C}$ and another combination $\mathrm{A}$ and $\mathrm{B}$ and $\mathrm{c}$ (lowercase notation means "the absence of C") which are both shared only by private veterinarians, then it is irrelevant whether $\mathrm{C}$ is present or absent. We can simply say that private veterinarians share the combination $\mathrm{A}$ and $\mathrm{B}$ (regardless of whether $\mathrm{C}$ is present or absent). An automated procedure called 'logical minimization' eliminates irrelevant attitudes, using the software fs/QCA 2.5. This is a very straightforward procedure that relies on basic set theory: A*B is the same as $\mathrm{A}^{*} \mathrm{~B} * \mathrm{C}+\mathrm{A}^{*} \mathrm{~B} * \mathrm{c}$, where $*$ indicates the Boolean $\mathrm{AND}$ and + indicates the Boolean OR. For indepth explanations of this method, see Fiss (2011), Ragin (2000) and Schneider and Wagemann (2012).

Obviously, street-level bureaucrats refer to attitudes to different degrees. Fuzzy set scores, ranging from 0 to 1 , indicate whether the attitude (the 'set') is present or absent, and to what degree. In a process termed 'calibration', measurement values are attributed to fuzzy set scores based on substantive and theoretical knowledge. The 'crossover point' of 0.5 is crucial: it establishes the qualitative difference in kind between set membership or non-membership. ${ }^{3}$ For example, for the set 'dilemma between rule pressure and professional norms', our respondents could rate the usefulness of the biannual visits on a Likert scale from 1 (very useful) to 4 (useless), and the crossover point was set at 2.5. If a veterinarian rates the biannual visits as

\footnotetext{
${ }^{3}$ Each case displays each configuration to a degree but has membership above 0.5 in only one of them.
} 
rather useless (3), she experiences a dilemma (fuzzy value of 0.7 ). However, her dilemma is less pronounced than that of another veterinarian who rated the visits with 4 (useless; fuzzy score of 1 , see Table 4 below). If a veterinarian rated the visits as rather or very useful, she did not experience a dilemma - again, to differing degrees.

We used three simple measures to deal with the analytic implications of the skewed data structure (Schneider and Wagemann 2012, 244-249). First, we analyse a large set of private veterinarians. In large- $\mathrm{N}$ analyses, measurement error could be an issue: hence, we should not afford attitudes shared by only very few private veterinarians the same importance as those shared by many private veterinarians (Maggetti and Levi-Faur 2013). We therefore exclude from the analysis purely private configurations displayed by only one or two private veterinarians (a so-called frequency threshold; see Fiss 2011, 403, 407). Conversely, with the small set of public veterinarians, a frequency threshold would cause us to lose important empirical information. As Figure 1 below shows, only two configurations feature more than two public veterinarians. It is not recommended to use a frequency threshold with such low case numbers (Maggetti and Levi-Faur 2013). Second, two parameters of fit called consistency and coverage often serve to evaluate the results of explanatory configurational set-theoretic analyses. However, the unequal case distributions distort these indicators. ${ }^{4}$ Fortunately, there is no need to base our descriptive analysis on them: we can detect private-only, public-only and

\footnotetext{
${ }^{4}$ The consistency measure, ranging from 0 to 1 , expresses the degree to which the statement 'membership in $\mathrm{X} \leq$ membership in Y' holds for all cases (Schneider and Wagemann 2012, 127-128). Consistency is artificially low for the public only configurations, where $\mathrm{Y}$ is skewed toward 0 , and generally high for the private only configurations. The exact opposite holds for the coverage scores.
} 
mixed attitudes simply by looking at case numbers. Applying these two strategies to remedy skewness, we define public-only configurations as those with $\mathrm{N}$ (private) $=0$, private only configurations as those with $\mathrm{N}$ (public) $=0$ and $\mathrm{N}$ (private) $\geq 3$, and mixed types as configurations with $\mathrm{N}$ (private) $\geq 1$ and $\mathrm{N}$ (public) $\geq 1$.

Additionally, third, we tested how robust the results are in response to these strategies (Schneider and Wagemann 2012, 244-249) (Figures A1 and A2, appendix). When analysing the private-only attitudes without a frequency threshold, logical minimization yields several equally plausible results, which renders them hardly interpretable (Baumgartner and Thiem 2015). This test confirms that it is useful to apply a frequency threshold. An analysis of mixed attitudes applying a frequency threshold for private veterinarians robustly supports all our substantive conclusions (Maggetti and Levi-Faur 2013).

\section{Measurement and calibration}

Table 4 summarizes the measurement and calibration of the attitudes, including the detailed survey questions and answer categories. The raw data will be posted at http://www.compasss.org/bibdata.htm. Whenever available, we chose identical survey questions for public and private veterinarians. Some other items measured the same attitude considering the specific circumstances facing public or private veterinarians. We combine such functionally equivalent items with the logical OR. This minimizes the impact of missing values on the sample (Schneider and Wagemann 2012, 45-47). Most survey items used a four-value Likert scale. Here we applied the so-called direct calibration method, using a logistic function to fit the raw data between the three fuzzy set anchors at 1 (full membership), 0.5 (crossover point), and 0 (full non-membership). As explained earlier, the crossover point at 2.5 indicates the qualitative difference between the first two and the last two answer categories (e.g., [rather] 
disagree versus [rather] agree). Those items in Table 4 without a crossover point were calibrated as dichotomous 'crisp' sets (Schneider and Wagemann 2012, 35-38).

-- Insert Table 4 here --

\section{Results}

We now discuss what types of attitudes and peculiar patterns we observed.

\section{Types of attitudes}

Figure 1 displays the 42 of the 128 possible configurations of street-level attitudes that we observed empirically. ${ }^{5}$ Values of 1 for an attitude indicate fuzzy set scores above 0.5 , values of 0 indicate fuzzy set scores below 0.5 . Three features stand out. First, the vast majority of both public and private veterinarians refer strongly to professional values. This reflects their shared professional background and general preferences for autonomy (Lipsky 1980/2010). In other words, virtually all street-level bureaucrats see themselves as professionals; a basic - in this sense, trivial - feature. Second, the public-only configurations (rows shaded white in Figure 1) represent only three public veterinarians. Essentially, we cannot identify empirically relevant 'public only' types of street-level attitudes because there are not enough public veterinarians.

\footnotetext{
${ }^{5}$ Rather than being attributable to a small N, this amount of limited empirical diversity (67 per cent) indicates that our data are clustered.
} 
The subsequent analysis therefore focuses on private only and mixed attitudes. Third, 16 private only configurations do not pass the frequency threshold (grey font colour in Figure 1). This produces a dropout of 24 private veterinarians ( 8.2 per cent).

-- Insert Figure 1 here -

\section{Salient patterns}

Logical minimization then reveals six mixed (Figure 2) and seven private-only (Figure 3) types of street-level attitudes. In these figures, black dots indicate that an attitude is present, and white dots indicate that it is absent. Blank spaces mean that an attitude is irrelevant. For example, the first row of Figure 2 shows the following type of mixed attitude: strong reference to rule (STATE), incentive (MARK), vocational (PROF) and societal (SOC) pressure and the absence of a dilemma between state and the market accountability (dmark). Dilemmas between rule and vocational pressure (DPROF) or societal pressure (DSOC) are irrelevant. The first column tells us that 47 street-level bureaucrats display this configuration of attitudes. Rather than discussing each type in depth, we simplify our discussion of the results and focus only on those attitudes shared by more than 90 per cent of the cases. Vertical boxes highlight these dominant common patterns. ${ }^{6}$ We illustrate these patterns using interview excerpts translated from German.

\footnotetext{
${ }^{6}$ These dominant common patterns are peculiar only to mixed or private-only street-level attitudes in combination
} 
Figure 2 illustrates the attitudes that public and private veterinarians have in common. Dilemmas are relatively rare. However, all mixed attitudes combine a strong reference to professional values with strong reference to either market norms or societal pressure. The suggestions of a public veterinarian on how to improve the OVMP illustrate this constellation:

[MARK] A model that allows the veterinarians to sell drugs to livestock owners for onfarm storage, coupled with continuous education, is more efficient than increased documentation and checks (...) [PROF] it takes too long until medical products authorized in the European Union are available in Switzerland (...) It is good that import authorizations are possible; this should be eased (...) The different risks posed by premises of different sizes and with different species should be considered more (...) [SOC] We shouldn't regulate even more. It is too much of a police-patrol law.

-- Insert Figure 2 here --

Going back to the case numbers in Figure 1, we see that these mixed attitudes cover the majority of the public veterinarians, but only 19 per cent of the private veterinarians. Accordingly, Figure 3 reveals a strong cluster of uniquely private street-level attitudes. ${ }^{7}$ Contrary to our

with the other attitudes displayed in Figures 2 and 3. They are part of the identified types of veterinarians' attitudes in the vast majority of the cases, but do not represent types of street-level attitudes on their own (Schneider and Wagemann 2012, 281).

${ }^{7}$ The question arises whether these clusters are only an artefact of the skewed data structure, which implies a much higher probability for private veterinarians to display an attitude than for public veterinarians. We argue that this is not the case. Let us go back to Figure 1 and assume that private veterinarians are equally likely to have a mixed 
sectoral hypothesis and despite an empirical tendency, strong reference to the market norms is not a dominant attitude that is only typical of for-profit street-level bureaucrats. By contrast, all these private-only street-level attitudes combine a strong reference to professional values with either a clash between rule pressure and societal pressure, or a tension between rule pressure and incentive pressure. These dilemmas of private veterinarians reflect their conflicting roles within the implementation arrangement of the OVMP, where they are simultaneously implementing agents, target group, and professionals.

-- Insert Figure 3 here --

Private veterinarians perceive the policy to be incompatible not only with the demands of their clients but also with their own needs as clients of the policy. As expected, the frequency and quality of their interaction with the farmers seems to strengthen participatory accountability. The succinct answer of a private veterinarian to the question which negative consequences the OVMP had, expresses this tension:

attitude (the 9 rows shaded grey) or a private attitude (the 14 rows shaded dark that pass the frequency threshold). This would be the case if there really were no systematic difference between public and private attitudes. Based on the configurations observed in Figure 1, we compared the expected distribution of private veterinarians in private-only and mixed configurations with the empirically observed distribution using a simple Chi-square statistic. If private veterinarians were distributed in a proportion of 9 (mixed) to 14 (private only), this would result in a frequency of 61 per cent of all private veterinarians displaying a private-only type. Instead, we observe 81 per cent. This difference is statistically significant, $\chi 2(1, \mathrm{~N}=269)=26.32, \mathrm{p}<.001$. If there were no systematic difference between public and private street-level attitudes, then more private veterinarians than observed would share their attitudes with public veterinarians. 
[DSOC] A veterinarian needs drugs to work. No animal gets better by filling in papers.

The results also illustrate a widespread tension between the expectations of the clients as customers and the rules of the policy (DMARK). Sager et al. $(2014,17,19-20)$ have described this tension as follows:

Some livestock owners exert significant pressure on veterinarians to stretch the regulations to their own favour (...) the easiest way for veterinarians to avoid a loss of customers is if they can bypass unfavourable provisions without this being discovered. An effective enforcement of the OVMP's regulations is a potential threat to the veterinarians' business. (...) This creates a dilemma where economic interests often impede the effective enforcement of the OVMP.

As rule pressure and incentive pressure prove incompatible, the private veterinarians are torn between the state and the market. Sager et al. (2014) describe how the role of market actor overrules that of implementing agent. The opposite is also possible, if the policy causes negative financial consequences for the for-profit street-level bureaucrats. The words of a young veterinarian, describing the consequences of the OVMP for his professional routine may best illustrate this dilemma:

[DMARK] I have one hour of additional work per day, without any added value for my practice. How am I supposed to start a business like this?

We now discuss the implications of these findings for our hypotheses. 


\section{Discussion}

The introduction of market principles into policy implementation in face created a 'tension between performance and representation' (Pierre 2009, 603) in the attitudes of the street-level bureaucrats we studied here.

Our findings do not support the sectoral hypothesis: strong reference to market norms is not typical of for-profit street-level bureaucrats only. Rather, both state and market actors can refer to market incentives. They vary greatly in how they practise accountabilities and experience dilemmas. However, we also found systematic differences between public and private veterinarians (categorical hypothesis refuted). In support of the private dilemma hypothesis, we find that the vast majority of private veterinarians do not share their attitudes with public veterinarians. Under certain circumstances, for-profit street-level bureaucrats typically find it particularly difficult to reconcile the rules of the state with the incentives of the market and/or the needs of their clients. The institutionally complex, hybrid implementation arrangement of the OVMP and its incentive structure create conflicting accountabilities for private veterinarians. Simultaneously, and although street-level bureaucrats often face conflicting demands, these problems affect the public veterinarians less.

We illustrated our theoretical argument with a skewed set of street-level bureaucrats that were particularly likely to be held accountable by the market and their clients. The effects of regulatory delegation are heavily context-dependent (Overman 2016). Regulatory contexts comparable to ours have a strong multi-level structure with low levels of oversight of streetlevel bureaucrats. They involve an economic dependence between the implementing agent and addressees (e.g., food safety audits in the United States).Other populations or different policy areas might see different responses to hybridization (e.g., Fossestøl et al. 2015). Rather than 
providing a statistically representative theory test, our analysis has generated some new insights with interesting implications.

\section{Conclusion}

Research consistently shows that the delegation of regulatory tasks to market actors fails to deliver the expected results (Overman 2016). Indeed, market elements in policy implementation can worsen output performance instead of improving it (Dias and Maynard-Moody 2006; Thomann et al. 2016). By linking the hybridity literature with accountability concepts and moving beyond case studies to analyse a unique large set of for-profit street-level bureaucrats, our study sheds light on the still poorly understood mechanisms that underlie such findings. We find that the institutional complexity of hybrid arrangements 'is making matters increasingly complex for practitioners - especially with regard to the proliferation of expectations made of them' (Buffat 2014, 71). The many accountabilities of for-profit policy implementers can further increase the inherent dilemmas of street-level work (Fossestøl et al. 2015; Koppell 2005).

This analysis has focused on frontline attitudes. We lack data on the performance of individual for-profit implementers to directly link these attitudes with behaviour. How the observed clash of accountabilities affects performance remains an empirical question for future research. Yet Sager et al. (2014) have shown that about fifty per cent of the private veterinarians substantially neglect their implementation duties. The empirical link between these accountability dilemmas and the actual performance of for-profit street-level bureaucrats requires systematic attention. Many argue that attempts to do equal justice to contradictory accountabilities are likely to fail, which renders compliance impossible (Koppell 2005; Pache and Santos 2010). These conflicting accountabilities might therefore lead for-profit policy implementers to favour 
economic performance over central policy goals like equality, fairness and inclusion especially when effective oversight is absent (Considine and Lewis 1999, 471; Ebrahim et al. 2014; Lytton and McAllister 2014; Pache and Santos 2010). This is a result not of lacking accountability in the for-profit sector, but of ‘too much' accountability (Koppell 2005).

Our analysis has several governance implications. Arrangements in which implementing agents economically depend upon the target group they control, without adequate monitoring, are not promising. Rather than assuming a priori benefits of marketization, policymakers and practitioners should consider and address possible mismatches when assigning implementation duties to for-profit agents (Overman 2016). As Deleon $(1998,554)$ highlights, 'the challenge for government is to identify the varying task environments in each sphere of action and use mechanisms of accountability that are appropriate in this area' (see also Mashaw 2005, 15, 24). The extended accountability regimes framework is a useful analytic tool for both experts and practitioners to anticipate accountabilities and possible dilemmas of street-level bureaucrats. The framework applies insights from hybridization research to individual implementing agents (Pache and Santos 2010, 2013; Skelcher and Smith 2015), operationalizes the accountability concept empirically (Behn 2011; Bovens et al. 2014; Busuioc and Lodge 2016; Mashaw 2005), and accounts for the introduction of market elements into street-level bureaucracy (Koppell 2010).

Hybridization research tells us that actors in hybrid arrangements demonstrably develop strategies and practices that integrate different logics over time (Skelcher and Smith 2015; Fossestøl et al. 2015). These responses vary, depending on the nature of demands and the degree to which an organization represents conflicting demands (Pache and Santos 2010). They range from decoupling (prioritizing one logic over another) through compromise (altering demands to restore balance) to the coupling of competing demands by reconciling their intact elements 
(Pache and Santos 2013). Applied to the Swiss case, it could become economically viable for private veterinarians to perform their control duties adequately.

Practical proposals to address accountability dilemmas often focus on organizations as a whole (Pache and Santos 2010) or on 'managerial dilemmas' (Seibel 2015), rather than on individual service deliverers. Ebrahim et al. (2014) discuss how several governance tools may prevent 'mission drift': monitoring of social and commercial activities or manager performance (e.g., quality controls), and opportunities for representation and participation of beneficiaries. However, the decentralized governance structure studied here impedes effective monitoring, and lacks the organizational embedding necessary to implement such measures. Lytton and McAllister (2014) highlight the usefulness of buyer vigilance; for example, consumers in the United Kingdom can opt for brands that ensure rigorous on-farm controls. Other mechanisms to change accountability structures include tort litigation, liability insurance, accreditation, benchmarking, media coverage and network configurations.

The results presented here highlight that such responses could differ even within organizations and below managerial levels. Notably, private street-level bureaucrats, too, display the strikingly high levels of observable professionalism that are at the heart of street-level bureaucracy (Brodkin 2012; Hupe and van der Krogt 2013; Lipsky’s 1980/2010). Capitalizing on these strong professional norms and values, mechanisms of self-regulation could countervail dilemmas (Lytton and McAllister 2014; Pache and Santos 2013). For example, the institutionalization of professional networks could enable opportunities of exchange that are likely to influence the individual coping decisions. Professional organizations could apply 'naming and shaming' strategies to foster good control practices. Following this, the extended accountability regimes framework fruitfully applies established concepts of street-level bureaucracy to the study of hybrid, for-profit policy implementation. Moreover, it paves the 
way for a better understanding of the potential benefits and pitfalls of such arrangements.

\section{References}

Baumgartner, M. and A. Thiem. 2015. 'Model Ambiguities in Configurational Comparative Research', Sociological Methods \& Research, DOI: 10.1177/0049124115610351.

Behn, R.D. 2001. Rethinking democratic accountability. Washington, DC: Brookings Institution Press.

Bovens, M., R.E. Goodin and T. Schillemans. 2014. The Oxford Handbook of Public Accountability. Oxford: Oxford University Press.

Brodkin, E.Z. 2012. 'Reflections on Street-Level Bureaucracy: Past, Present, and Future', Public Administration Review, 72, 6, 940-949.

Buffat, A. 2014. ''Public on the outside, private on the inside': the organizational hybridization, sense of belonging and identity strategies of the employees of a public unemployment insurance fund in Switzerland', International Review of Administrative Sciences, 80, 1, 70-88.

Busuioc, E.M. and M. Lodge. 2016. 'The reputational basis of public accountability', Governance, 29, 2, 247-263.

Considine, M. and J.M. Lewis. 1999. 'Governance at Ground Level: The Frontline Bureaucrat in the Age of Markets and Networks', Public Administration Review, 59, 6, 467-480.

Considine, M. and J.M. Lewis. 2003. 'Bureaucracy, Network, or Enterprise? Comparing Models of Governance in Australia, Britain, the Netherlands, and New Zealand', Public Administration Review, 63, 2, 131-140.

Considine, M., J.M. Lewis and Siobhan O’Sullivan. 2011. 'Quasi-markets and service delivery 
flexibility following a decade of employment assistance reform in Australia', Journal of Social Policy, 40, 4, 811-833.

Deleon, L. 1998. 'Accountability in a 'Reinvented' Government', Public Administration, 76, 3, 539-558.

Dias, J.J. and S. Maynard-Moody. 2006. 'For-profit welfare: contracts, conflicts, and the performance paradox', Journal of Public Administration Research and Theory, 17, 2, 189-211. Ebrahim, A., Battilana, J. and J. Mair. 2014. 'The governance of social enterprises: Mission drift and accountability challenges in hybrid organizations', Research in Organizational Behavior, 34, 81-100.

Fiss, P.C. 2011. 'Building better causal theories: A fuzzy set approach to typologies in organization research', Academy of Management Journal, 54, 2, 393-420.

Fossestøl, K., Breit, E., Andreassen, T.A. and L. Klemsdal. 2015. 'Managing Institutional Complexity in Public Sector Reform: Hybridization in Front-Line Service Organizations', Public Administration, 93, 2, 290-306.

Hupe, P.L. and A. Buffat. 2014. 'A Public Service Gap: Capturing Contexts in a Comparative Approach of Street-Level Bureaucracy', Public Management Review, 16, 4, 548-569.

Hupe, P.L. and M.J. Hill. 2007. ‘Street-Level Bureaucracy and Public Accountability’, Public Administration, 85, 2, 85-102.

Hupe, P.L. and T. Van der Krogt. 2013. 'Professionals Dealing with pressure', in M. Noordegraaf and B. Steijn (eds), Professionals Under Pressure: Perspectives on professionals and professionalism. Amsterdam: Amsterdam University Press, pp. 55-72.

Koppell, J.GS. 2010. 'Administration without borders', Public Administration Review, 70.s1, s46-s55. 
Koppell, J. GS. 2005. 'Pathologies of accountability: ICANN and the challenge of "multiple accountabilities disorder"”, Public Administration Review, 65, 1, 94-108.

Levi-Faur, D. 2011. 'Regulation and regulatory governance', in D. Levi-Faur (ed.), Handbook on the Politics of Regulation. Cheltenham, UK: Edward Elgar Publishing, pp. 3-25.

Lipsky, M. 1980/2010. Street-Level Bureaucracy: The Dilemmas of the Individual in Public Services. New York: Russell Sage Foundation.

Lytton, T.D. and L.K. McAllister. 2014. 'Oversight in Private Food Safety Auditing: Addressing Auditor Conflict of Interest', Wisconsin Law Review.

Maggetti, M. and D. Levi-Faur. 2013. 'Dealing with Errors in QCA', Political Research Quarterly, 66, 1, 198-204.

Mashaw, J.L. 2005. 'Structuring a 'Dense Complexity': Accountability and the Project of Administrative Law', Issues in Legal Scholarship, 4, 1-38.

May, P.J. and S.C. Winter. 2009. 'Politicians, managers, and street-level bureaucrats: Influences on policy implementation', Journal of Public Administration Research and Theory, $19,3,453-476$.

Oberfield, Z.W. 2016. 'A Bargain Half Fulfilled Teacher Autonomy and Accountability in Traditional Public Schools and Public Charter Schools', American Educational Research Journal, 53, 2, 296-323.

Overman, S. 2016. 'Great Expectations of Public Service Delegation: A systematic review', Public Management Review 18, 8, 1238-1262.

Pache, A., and F. Santos. 2010. 'When worlds collide: The internal dynamics of organizational responses to conflicting institutional demands', Academy of Management Review, 35, 3, 455476. 
Pache, A., and F. Santos. 2013. 'Inside the hybrid organization: Selective coupling as a response to competing institutional logics', Academy of Management Journal 56, 4, 972-1001.

Pierre, J. 2009. 'Reinventing governance, reinventing democracy?', Policy and Politics, 37, 4, 591-609.

Ragin, C.C. 2000. Fuzzy-Set Social Science. Chicago and London: University of Chicago Press. Sætren, H. 2014. 'Implementing the third generation research paradigm in policy implementation research: An empirical assessment', Public Policy and Administration, 29, 2, 84-105.

Sager, F., Thomann, E. Zollinger, C., van der Heiden, N. and C. Mavrot. 2014. 'Street-level bureaucrats and New Modes of Governance - How Conflicting Roles Affect the Implementation of the Swiss Ordinance on Veterinary Medicinal Products', Public Management Review, 16, 4, 481-502.

Sager, F., Van der Heiden, N., Mavrot, C., Thomann, E., Zollinger, C. and M. Hinterleitner. 2012. Formative Evaluation Vollzug Tierarzneimittelverordnung (TAMV). Study mandated by the Swiss Federal Office of Public Health. Bern, Center of Competence for Public Management. Schillemans, T. and M. Busuioc. 2015. 'Predicting Public Sector Accountability: From Agency Drift to Forum Drift', Journal of Public Administration Research and Theory, 25, 1, 191-215.

Schneider, C.Q. and C. Wagemann. 2012. Set-Theoretic Methods for the Social Sciences. A Guide to Qualitative Comparative Analysis. New York: Cambridge University Press.

Seibel, W. 2015. 'Studying hybrids: Sectors and mechanisms', Organization Studies, 36, 6, $697-712$

Skelcher, C. and S.R. Smith. 2015. ,Theorizing Hybridity: Institutional Logics, Complex Organizations, and Actor Identities: The case of Nonprofits', Public Administration, 93, 2, 433 - 
448.

Smith, S.R. and M. Lipsky. 2009. Nonprofits for hire: The welfare state in the age of contracting. Harvard: Harvard University Press.

Thomann, E. 2015. 'Is output performance all about the resources? A fuzzy-set Qualitative Comparative Analysis of street-level bureaucrats in Switzerland', Public Administration, 93, 1, 177-194.

Thomann, E., Lieberherr, E. and K. Ingold. 2016. 'Torn between state and market: Private policy implementation and conflicting institutional logics', Policy \& Society 35, 1, 57-69.

Tummers, L. 2012. 'Policy Alienation of Public Professionals: The Construct and its Measurement', Public Administration Review, 72 , 4, 516-525.

Tummers, L., B. Steijn and V. Bekkers. 2012a. 'Explaining The Willingness Of Public Professionals To Implement Public Policies: Content, Context, And Personality Characteristics', Public Administration, 90, 3, 716-736.

Tummers, L., B. Vermeeren, B. Steijn and V. Bekkers. 2012b. 'Public professionals and policy implementation: conceptualizing and measuring three types of role conflicts', Public Management Review, 14, 8): 1041-1059.

Verbruggen, P. and T. Havinga. Forthcoming, 2017. 'Hybridization of food governance: an analytical framework', in Verbruggen, P. and T. Havinga (eds), Hybridization of food governance: Trends, types and results. Edward Elgar. 


\section{Tables and Figures}

TABLE 1 Extended accountability regimes framework

\begin{tabular}{|c|c|c|c|c|}
\hline Key source & State & Market & Profession & Society \\
\hline Accountability & $\begin{array}{l}\text { Political- } \\
\text { administrative }\end{array}$ & $\begin{array}{l}\text { Customer- and } \\
\text { shareholder- } \\
\text { oriented }\end{array}$ & Vocational & Participatory \\
\hline 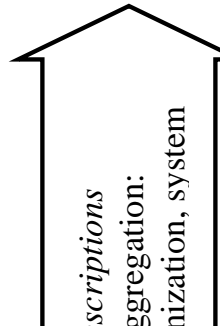 & Formal rules & $\begin{array}{l}\text { Cost minimization } \\
\text { Benefit } \\
\text { maximization } \\
\text { Customer } \\
\text { satisfaction } \\
\text { Shareholder value } \\
\text { creation } \\
\text { Competition }\end{array}$ & $\begin{array}{l}\text { Professional values, } \\
\text { norms, and attitudes } \\
\text { Good practice } \\
\text { Peer review }\end{array}$ & $\begin{array}{l}\text { Societal } \\
\text { expectations } \\
\text { Perceived clients' } \\
\text { needs }\end{array}$ \\
\hline 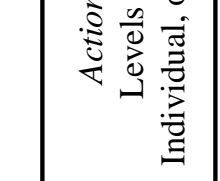 & Rule pressure & Incentive pressure & Vocational pressure & Societal pressure \\
\hline
\end{tabular}

Author's own elaboration, based on Mashaw (2005), Dias and Maynard-Moody (2006), Hupe and Hill (2007), Considine et al. (2011), Hupe and Van der Krogt (2013), Hupe and Buffat (2014). 
TABLE 2 A typology of street-level attitudes

\begin{tabular}{|c|c|c|c|c|}
\hline Source & State & Market & Profession & Society \\
\hline $\begin{array}{l}\text { Norm } \\
\text { reference }\end{array}$ & $\begin{array}{l}\text { 1. Reference to rule } \\
\text { pressure, e.g., } \\
-\quad \text { rules, tasks or } \\
\quad \text { targets } \\
-\quad \text { standard } \\
\quad \begin{array}{l}\text { operating } \\
\text { procedures or }\end{array} \\
\quad \text { contract } \\
\text { Examples: } \\
\text { Powerlessness } \\
\text { Personal } \\
\text { meaninglessness } \\
\text { Policy perception and } \\
\text { endorsement }\end{array}$ & $\begin{array}{l}\text { 2. Reference to } \\
\text { incentive pressure, } \\
\text { e.g., } \\
-\quad \text { goals of } \\
\text { efficiency, } \\
\text { financial } \\
\text { transparency and/ } \\
\text { or profit } \\
-\quad \text { customers' } \\
\text { demands } \\
-\quad \begin{array}{l}\text { goals of output } \\
\text { maximization / } \\
\text { expenditure } \\
\text { minimization }\end{array}\end{array}$ & $\begin{array}{l}\text { 3. Reference to } \\
\text { vocational pressure, } \\
\text { e.g., } \\
-\quad \text { internalized } \\
\text { professional } \\
\text { standards } \\
-\quad \text { professional } \\
\text { values }\end{array}$ & $\begin{array}{l}\text { 4. Reference to } \\
\text { societal pressure, e.g., } \\
-\quad \text { shared goals and } \\
\text { standard setting } \\
-\quad \text { clientele and } \\
\quad \text { societal goals }\end{array}$ \\
\hline $\begin{array}{l}\text { Dilemmas } \\
\text { with rule } \\
\text { pressure }\end{array}$ & -- & $\begin{array}{l}\text { 7. Competing } \\
\text { demands from rule } \\
\text { pressure and incentive } \\
\text { pressure }\end{array}$ & $\begin{array}{l}\text { 6. Competing } \\
\text { demands from rule } \\
\text { pressure and } \\
\text { vocational pressure }\end{array}$ & $\begin{array}{l}\text { 5. Competing } \\
\text { demands from rule } \\
\text { pressure and societal } \\
\text { pressure }\end{array}$ \\
\hline & & $\begin{array}{l}\text { Examples: } \\
\text { Financial loss due to } \\
\text { policy } \\
\text { Alienation of } \\
\text { customers / } \\
\text { shareholders due to } \\
\text { output tasks } \\
\text { Incentive pressure has } \\
\text { negative impact on } \\
\text { output delivery }\end{array}$ & $\begin{array}{l}\text { Examples: } \\
\text { Policy-professional } \\
\text { role conflict } \\
\text { Organizational- } \\
\text { professional role } \\
\text { conflicts }\end{array}$ & $\begin{array}{l}\text { Examples: } \\
\text { Policy-client role } \\
\text { conflict } \\
\text { Client } \\
\text { meaninglessness } \\
\text { Societal } \\
\text { meaninglessness }\end{array}$ \\
\hline
\end{tabular}

Own illustration, based on Mashaw (2005), Dias and Maynard-Moody (2006), May and Winter (2009), Considine et al. (2011), Tummers (2012), Tummers et al. (2012a, b), Hupe and Buffat (2014). 
TABLE 3 Public and private veterinarians compared

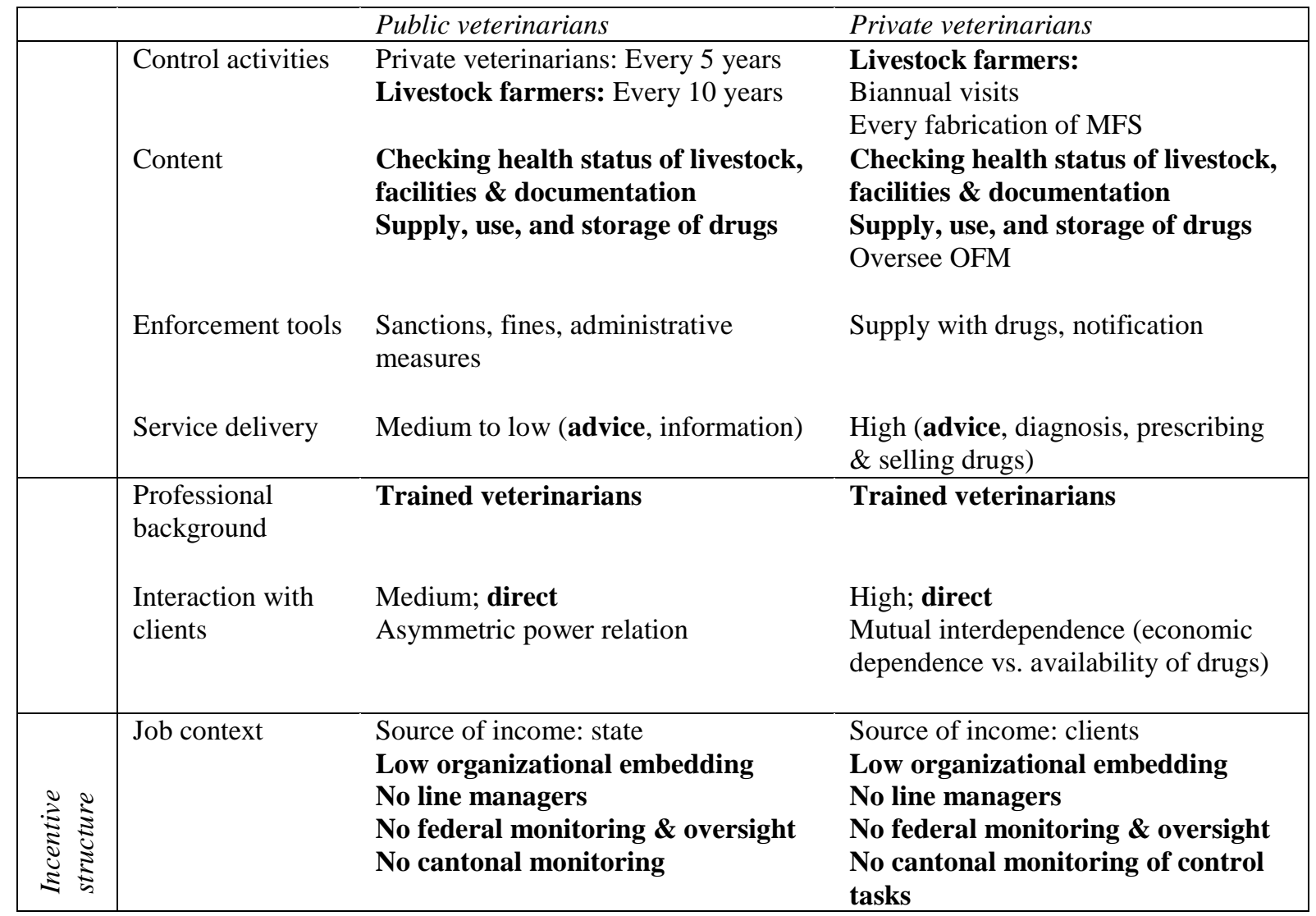

Boldface indicates commonalities between public and private veterinarians 


\begin{tabular}{|c|c|c|c|c|}
\hline \multirow[b]{2}{*}{ Set } & \multirow[b]{2}{*}{ Operationalization } & \multicolumn{3}{|c|}{ Calibration anchors } \\
\hline & & $\begin{array}{l}\text { Fully in } \\
\text { (1) }\end{array}$ & $\begin{array}{l}\text { Neither } \\
\text { in nor } \\
\text { out }(0.5)\end{array}$ & $\begin{array}{l}\text { Fully } \\
\text { out }(0)\end{array}$ \\
\hline & $\begin{array}{l}\text { STATE1: Overall, do you find the documentation provisions of the } \\
\text { OVMP suitable to achieve the policy's goals? }\end{array}$ & 1 & 2.5 & 4 \\
\hline & $\begin{array}{l}\text { STATE2: Overall, do you find the control system of the OVMP } \\
\text { suitable to achieve the policy's goals? }\end{array}$ & 1 & 2.5 & 4 \\
\hline & $\begin{array}{l}\text { MARK1: How would you rate the usefulness of the written } \\
\text { agreement (TAM-Vereinbarung) that enables private veterinarians to } \\
\text { dispense veterinary drugs to livestock farmers for on-farm storage? }\end{array}$ & 1 & 2.5 & 4 \\
\hline & $\begin{array}{l}\text { MARK2: How much effort would it be for you to store the } \\
\text { documents for } 5 \text { (instead of } 3 \text { ) years? }\end{array}$ & 1 & 2.5 & 4 \\
\hline & $\begin{array}{l}\text { DMARK1: As how wide-spread would you rate the use of veterinary } \\
\text { drugs by private veterinarians that is not in accordance with the } \\
\text { provisions of the OVMP? }\end{array}$ & $2,3,4$ & -- & 1 \\
\hline & $\begin{array}{l}\text { DMARK2: What financial consequences did the OVMP have for } \\
\text { you? }\end{array}$ & 2 & -- & 1,3 \\
\hline & $\begin{array}{l}\text { PROF1: Are you in favour of the possibility for private veterinarians } \\
\text { to import veterinary drugs for stockpiling? }\end{array}$ & 1 & 2.5 & 4 \\
\hline & $\begin{array}{l}\text { PROF2: Should the inspections be planned in a more risk-based } \\
\text { manner in your view? }{ }^{1}\end{array}$ & 1 & 2.5 & 4 \\
\hline & $\begin{array}{l}\text { DPROF1: Do you think the number of inspections that must be } \\
\text { carried out is adequate? }\end{array}$ & 4 & 2.5 & 1 \\
\hline & $\begin{array}{l}\text { DPROF2: Do you find the content of the inspections as required by } \\
\text { the OVMP to be practicable and does it make sense? }\end{array}$ & 4 & 2.5 & 1 \\
\hline & $\begin{array}{l}\text { DPROF3: How would you rate the usefulness of the required } \\
\text { biannual visits by private veterinarians to livestock farms if a written } \\
\text { agreement exists? }\end{array}$ & 4 & 2.5 & 1 \\
\hline & $\begin{array}{l}\text { DPROF4: Do you have the knowledge necessary to assume the task } \\
\text { as an FTVP? }\end{array}$ & 4 & 2.5 & 1 \\
\hline & $\begin{array}{l}\text { SOC1: In your opinion, are the regulations of the OVMP too } \\
\text { restrictive for certain sectors? }\end{array}$ & 1 & -- & 2 \\
\hline & $\begin{array}{l}\text { SOC2: How would you rate a possible sharpening of the } \\
\text { documentation provisions? }\end{array}$ & 4 & 2.5 & 1 \\
\hline & $\begin{array}{l}\text { DSOC1: In your view, do the withdrawal periods set out by the } \\
\text { OVMP ensure the safety of the food products of animal origin? }{ }^{1}\end{array}$ & 4 & 2.5 & 1 \\
\hline & $\begin{array}{l}\text { DSOC2: Has the OVMP contributed to an improvement or a decrease } \\
\text { in the availability of veterinary drugs on the market? }\end{array}$ & 3 & -- & 1,2 \\
\hline
\end{tabular}

\footnotetext{
Item for public veterinarians

Item for public \& private veterinarians $\quad$ Item for private veterinarians

Answer categories:

${ }^{1} 1=$ yes, $2=$ rather yes, $3=$ rather not, $4=$ no

${ }^{2} 1$ = very useful, $2=$ rather useful, $3=$ rather useless, $4=$ useless

${ }^{3} 1=$ yes, $2=$ no

${ }^{4} 1=$ very positive, $2=$ rather positive, $3=$ rather negative, $4=$ very negative

${ }^{5} 1$ = improvement, 2 = neither nor, $3=$ decline

${ }^{6} 1=$ very high, $2=$ rather high, $3=$ rather low, $4=$ very low

${ }^{7} 1=0-25 \%, 2=25-50 \%, 3=50-75 \%, 4=75-100 \%$

${ }^{8} 1=$ my costs have been reduced, $2=$ my costs increased, $3=$ my costs have not changed
} 
FIGURE 1 Types of street-level attitudes

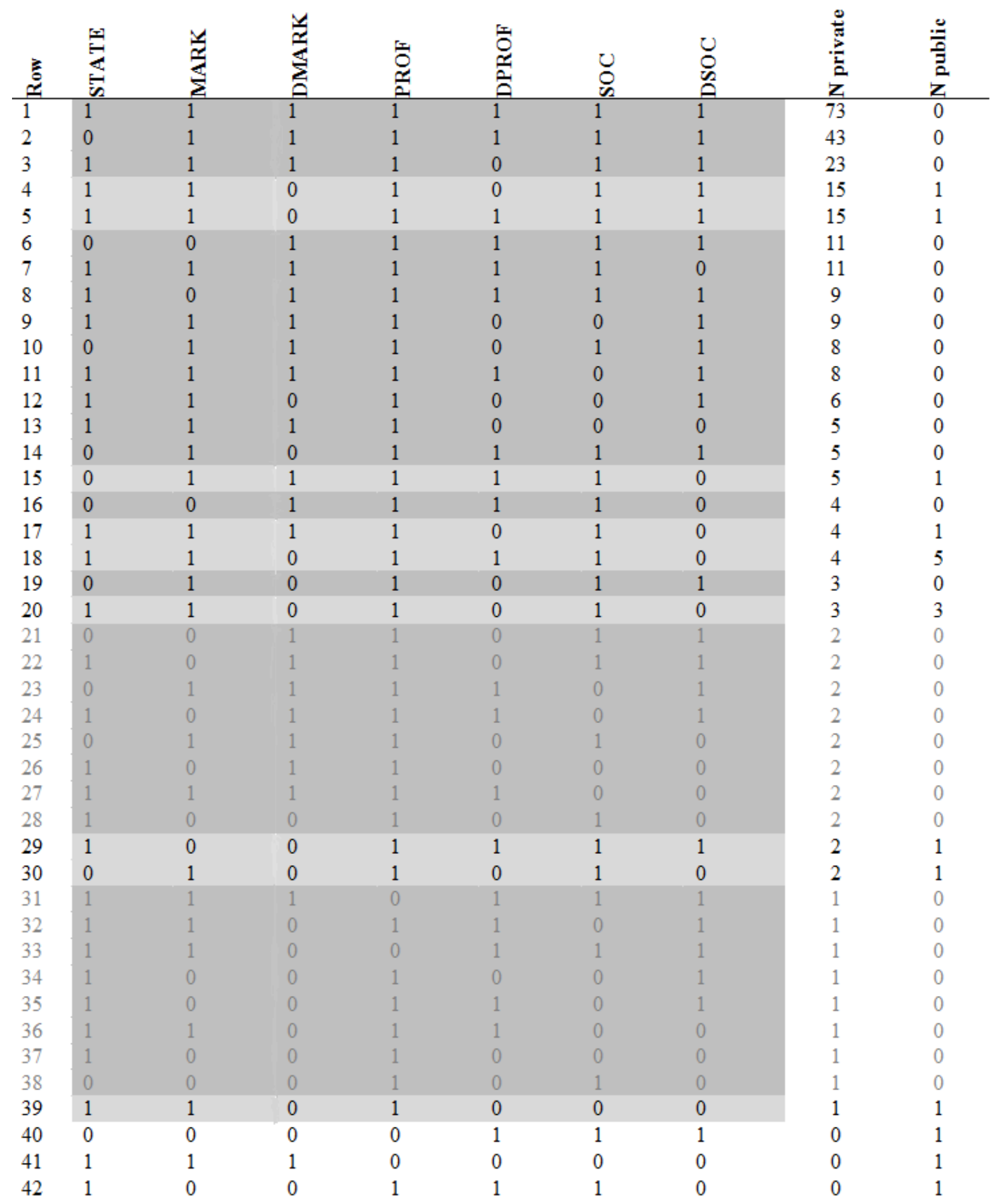

Grey font colour: private configuration does not pass frequency threshold of $=3$ (ex clusion from logical minimization).

O denotes fuzzy set scores $<0.5,1$ denotes fuzzy set scores $>0.5$.

Uniquely private types $\quad$ Mixed types Uniquely public types 
FIGURE 2 Mixed types of street-level attitudes

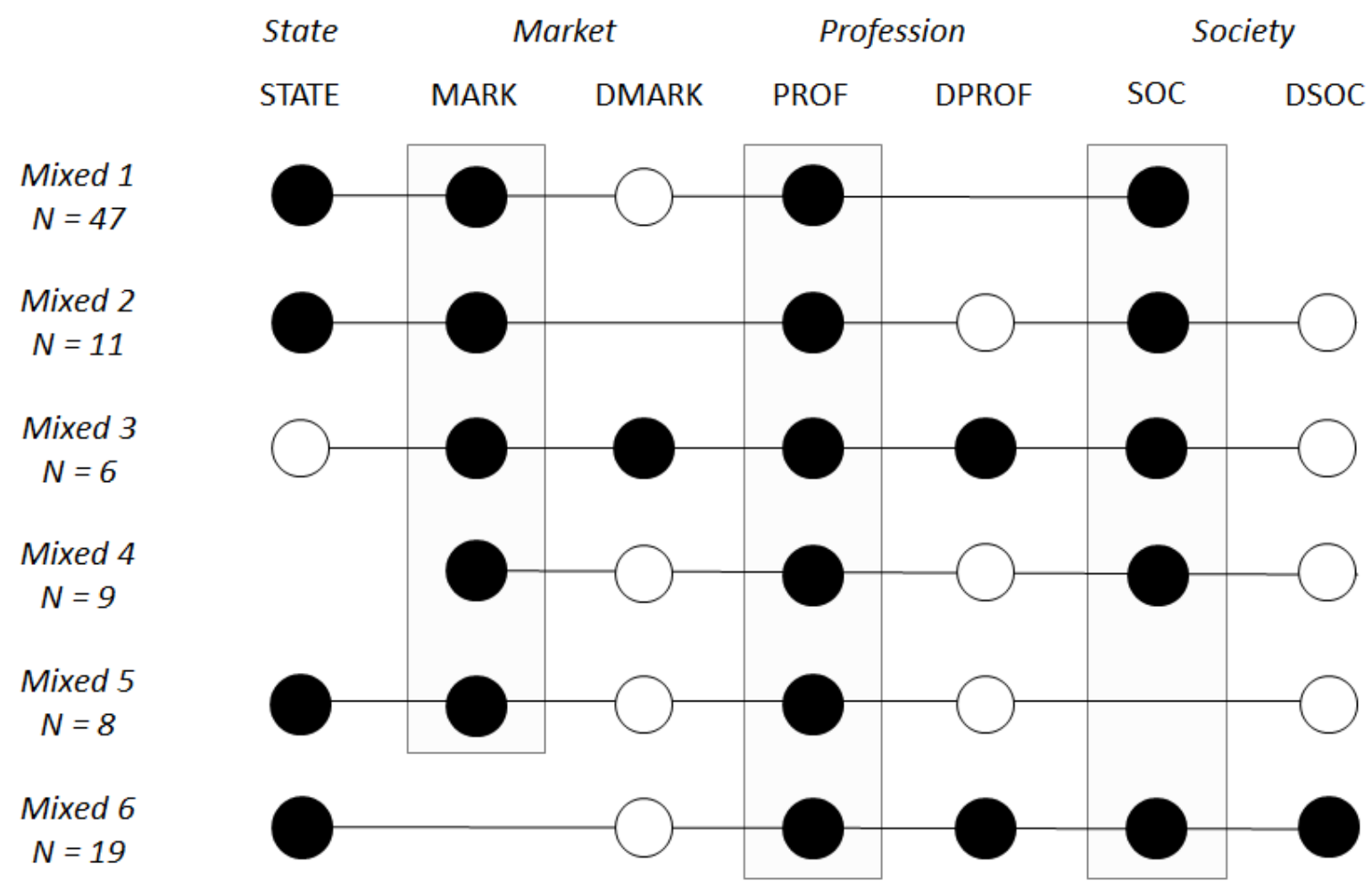

Black circles indicate the presence of a feature, and white circles, its absence. Blank spaces indicate that an attitude is irrelevant. Boxes denote attitudes displayed by more than 90 per cent of the cases $(\mathrm{N}=66)$. Cases can display more than one type.

Complex solution (consistency 0.811 , coverage 0.173 for outcome = mixed). Rows 4, 5, 15, 17, 18, 20, 29, 30, 39 of Figure 1. 
FIGURE 3 Private only types of street-level attitudes

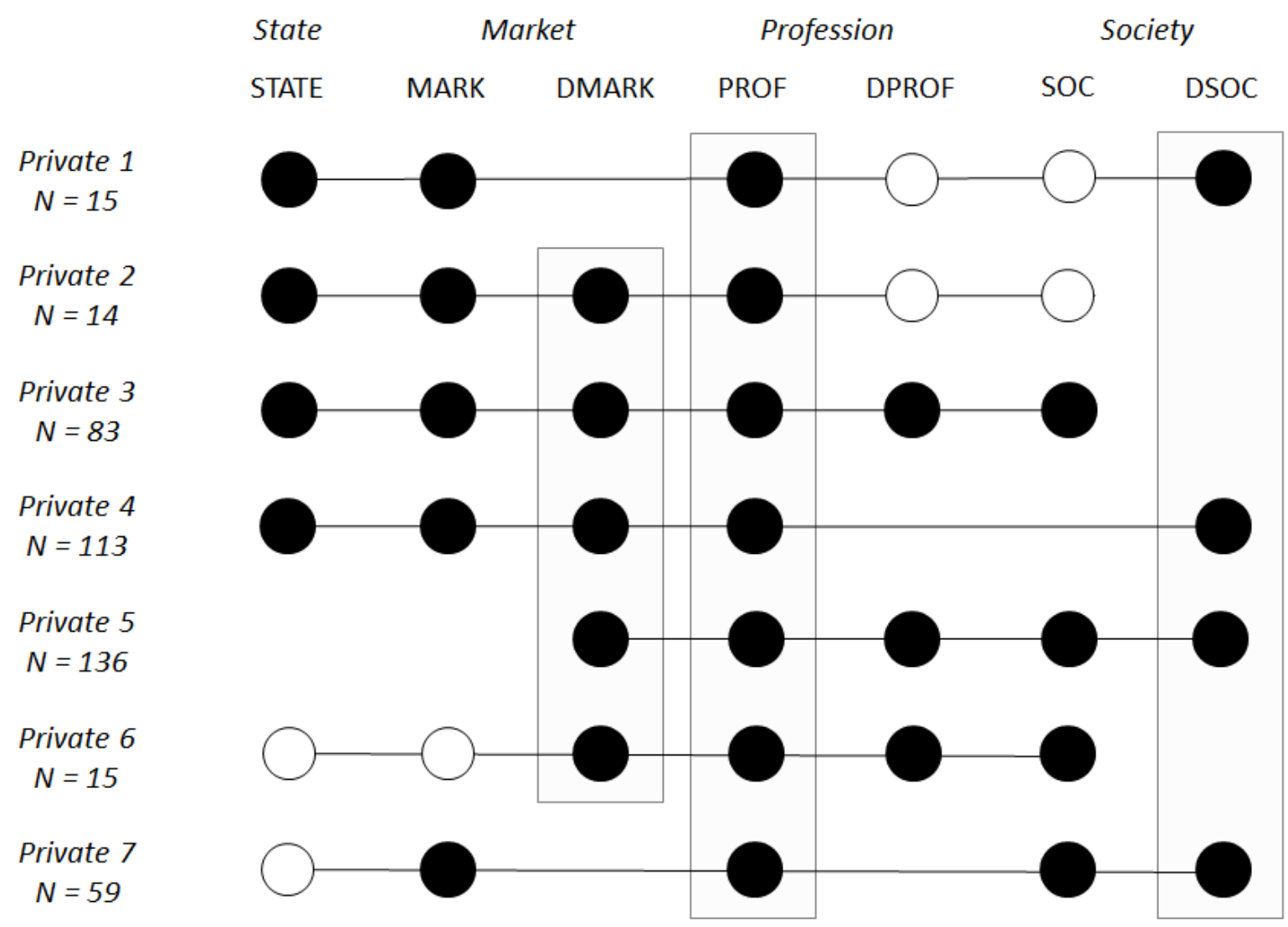

Black circles indicate the presence of a feature, and white circles, its absence. Blank spaces indicate that an attitude is irrelevant. Boxes denote attitudes displayed by more than 90 per cent of the cases $(\mathrm{N}=218)$. Cases can display more than one type.

Complex solution (consistency 0.986 , coverage 0.651 for outcome = private). Rows 1-3, 6-14, 16, 19 of Figure 1. 


\section{Appendix}

FIGURE A1 Mixed attitudes with frequency threshold for private veterinarians

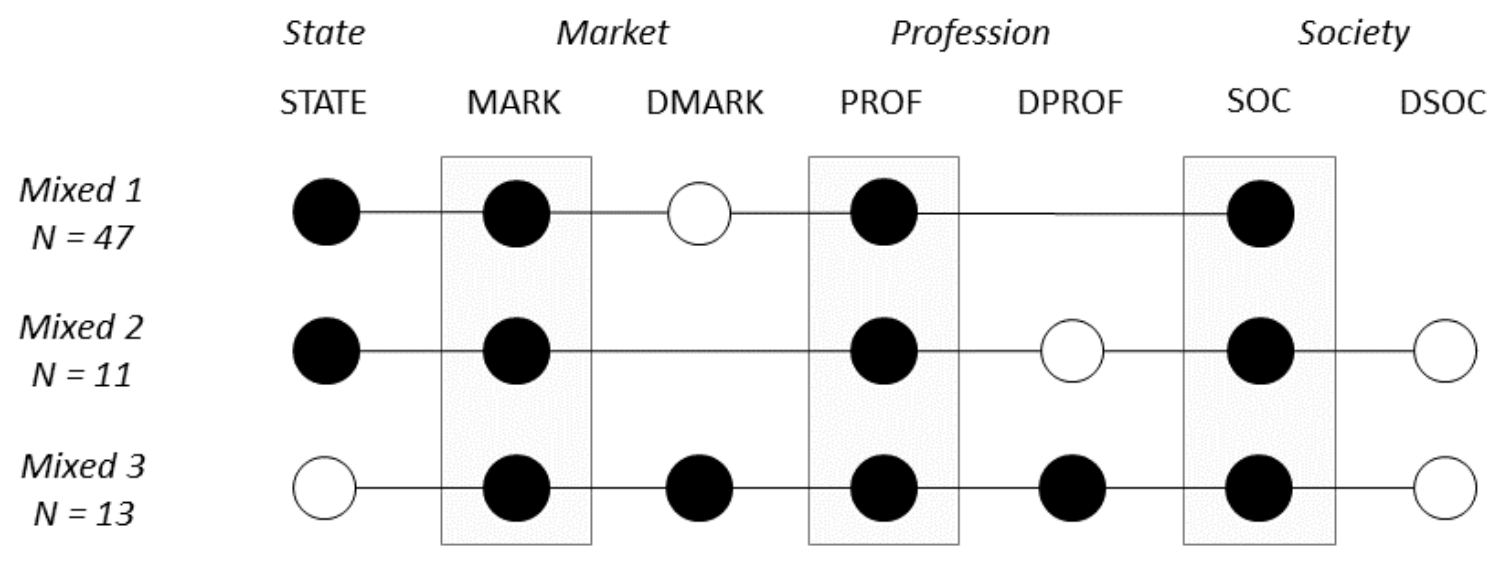

Complex solution (consistency 0.825 , coverage 0.163 for outome $=$ mixed).

Frequency cutoff $=3(\mathrm{~N}=58)$.

Rows 4, 5, 15, 17, 18, 20 of Figure 1. 
FIGURE A2 Private only attitudes without frequency threshold for private veterinarians

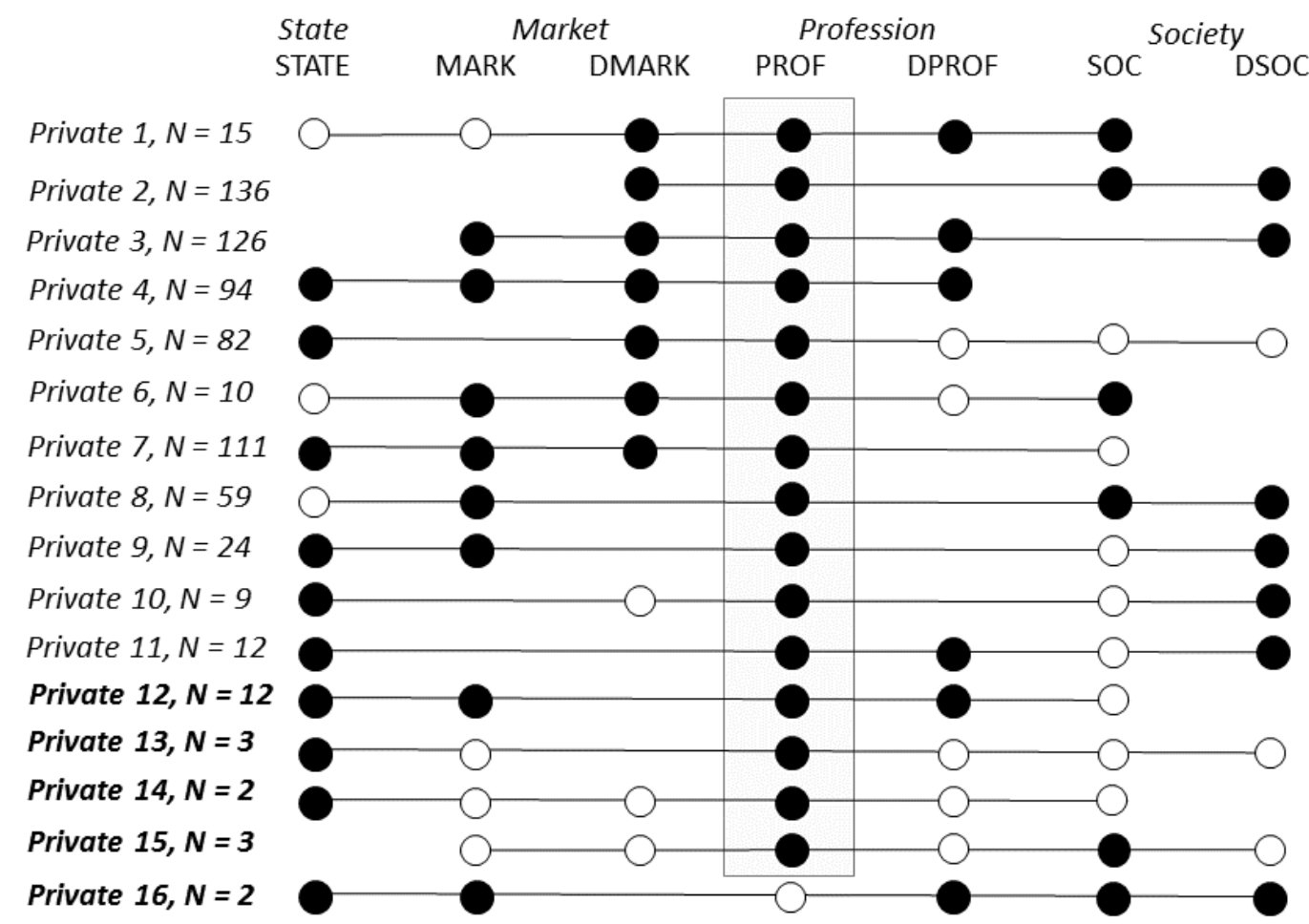

Complex solution, all PIs included (consistency 0.980 , coverage 0.728 for outcome = private) . $\mathrm{N}=242$. All rows shaded dark grey of Figure 1 .

Note: extreme amount of data ambiguity (multiple prime implicant charts with multiple prime implicants).

Bold: additional configurations not covered by those in Figure 3. 